\title{
NLRP12 modulates host defense through IL-17A-CXCL1 axis
}

\author{
S Cai ${ }^{1}$, S Batra ${ }^{1,2}$, F Del Piero ${ }^{1}$ and S Jeyaseelan ${ }^{1,3}$
}

We used an extracellular pathogen Klebsiella pneumoniae to determine the role of NLRP12 (NOD-like receptor (NLR) family pyrin domain containing 12 ) as this bacterium is associated with devastating pulmonary infections. We found that human myeloid cells (neutrophils and macrophages) and non-myeloid cells (epithelial cells) show upregulation of NLRP12 in human pneumonic lungs. NLRP12-silenced human macrophages and murine NIrp12 ${ }^{-1-}$ macrophages displayed reduced activation of nuclear factor- $\mathrm{kB}$ and mitogen-activated protein kinase, as well as expression of histone

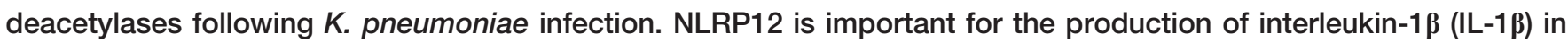
human and murine macrophages following $K$. pneumoniae infection. Furthermore, host survival, bacterial clearance, and neutrophil recruitment are dependent on NLRP12 following $K$. pneumoniae infection. Using bone marrow chimeras, we showed that hematopoietic cell-driven NLRP12 signaling predominantly contributes to host defense against $K$. pneumoniae. Intratracheal administration of either IL-17A + CD4 Tcells or chemokine (C-X-C motif) ligand 1 (CXCL1 +) macrophages rescues host survival, bacterial clearance, and neutrophil recruitment in NIrp12 ${ }^{-\prime}$ mice following $K$. pneumoniae infection. These novel findings reveal the critical role of NLRP12-IL-17A-CXCL1 axis in host defense by modulating neutrophil recruitment against this extracellular pathogen.

\section{INTRODUCTION}

Lower respiratory tract infections remain the most significant cause of worldwide infectious disease morbidity and healthcare costs. ${ }^{1}$ The Gram-negative extracellular bacterium, Klebsiella pneumoniae, induces lung destruction and multiple abscesses in the lung even with small inoculums. In the recent years, the extensive spread of multidrug-resistant $K$. pneumoniae strains has caused $\geq 50 \%$ mortality in the United States. and in the other parts of the world., ${ }^{2,3}$

Although over 20 members of the NOD-like receptor (NLR) family have been identified, the function of most of their members in contributing to host resistance against microbial infection has not been determined. Nevertheless, reports suggest a function of some NLRs or inflammasomes in sensing bacterial pathogens. ${ }^{4,5}$ Regarding $K$. pneumoniae infection, thus far only two types of inflammasomes have been reported to regulate host immunity to this aflagellated bacterium: NLR family pyrin domain containing 3 (NLRP3) ${ }^{6}$ and NLR family CARD domain containing 4 (NLRC4) inflammasomes. ${ }^{7,8}$

NLRP12 (aka NALP12/MONARCH-1/PYPAF-7) was shown as the first NLR to induce interleukin-1 $\beta$ (IL-1 $\beta$ ) maturation via the interaction with ASC (apoptosis-associated speck-like protein containing). ${ }^{9}$ Recent studies suggest that the NLRP12 inflammasome has a role in intestinal homeostasis ${ }^{10,11}$ and tumorigenesis. ${ }^{11,12}$ Regarding the role of NLRP12 in bacterial recognition, a recent report has shown that NLRP12 is important to contribute to anti-bacterial defense against Yesinia pestis following subcutaneous or intravenous challenge. ${ }^{13}$ The results also show that NLRP12-deficient (Nlrp12 ${ }^{-1-}$ ) animals had reduced survival and enhanced bacterial burden in the spleen, along with attenuated production of IL-18, IL-1 $\beta$, and interferon- $\gamma$ after $Y$. pestis infection. ${ }^{13}$ In another study using a very high dose of $K$. pneumoniae, results show reduced macrophage and lymphocyte influx and attenuated tumor necrosis factor- $\alpha$ (TNF- $\alpha$ ) levels in the

\footnotetext{
'Laboratory of Lung Biology, Department of Pathobiological Sciences and Center for Experimental Infectious Disease Research, Louisiana State University (LSU) School of Veterinary Medicine, Baton Rouge, Louisiana, USA and ${ }^{2}$ Section of Pulmonary and Critical Care, Department of Medicine, LSU Health Sciences Center, New Orleans, Louisiana, USA. Correspondence: S Jeyaseelan (jey@lsu.edu)

${ }^{3}$ Present address: Department of Environmental Toxicology, Southern University and A\&M College, Baton Rouge, LA, USA.

Received 9 December 2014; accepted 27 July 2015; published online 9 September 2015. doi:10.1038/mi.2015.80
} 
a
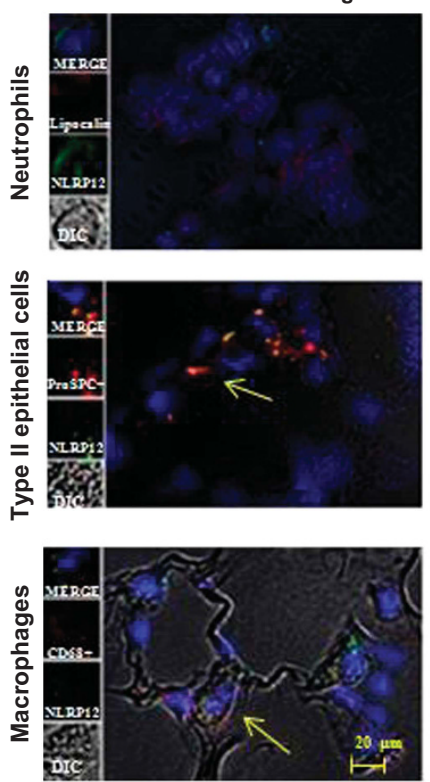

Pneumonic human lung
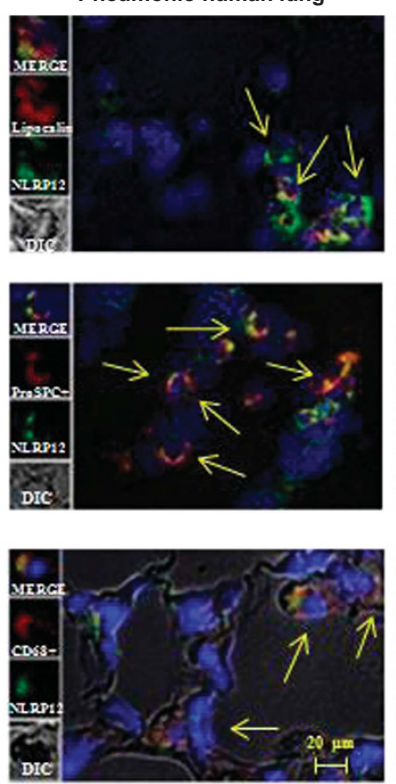

b
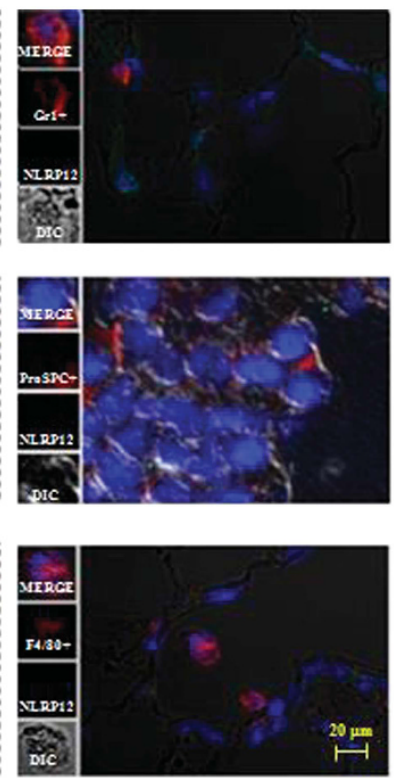

Pneumonic mouse lung
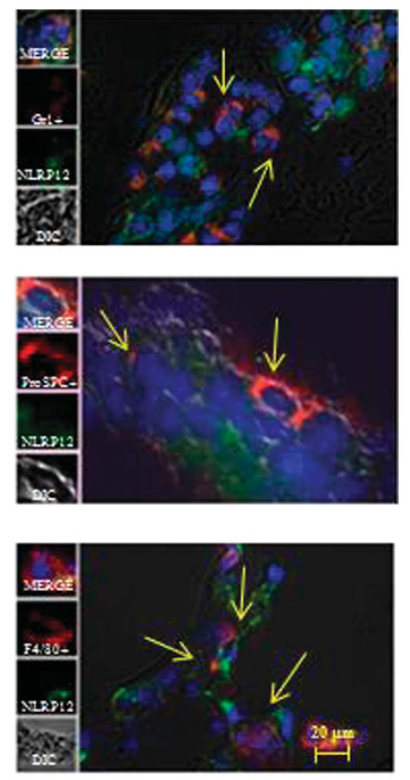

Figure 1 NLRP12 (NOD-like receptor family pyrin domain containing 12) expression is increased in myeloid cells (neutrophils and macrophages) and epithelial cells in the lung during acute lung injury/pneumonia. (a) Immunofluorescence microscopy was performed for NLRP12 expression in normal human (control) lung tissue and human lung tissue from bacterial pneumonia. NLRP12 is indicated by green staining, neutrophils are shown by lipocalin staining, epithelial cells are shown by pro-surfactant C (SPC) staining, and macrophages are shown by CD68 staining. (b) NLRP12 expression is enhanced in myeloid cells (neutrophils and macrophages) and epithelial cells in mouse lungs during pneumonia. NLRP12 is indicated by green staining, neutrophils are shown by Gr1 staining, epithelial cells are stained by pro-SPC staining, and macrophages are shown by F4/80 staining. This is a representative image of five sections with similar results. Original magnification, $\times 200$.

lungs following the infection, although neutrophil influx and bacterial clearance were not different between wild-type (WT) and Nlrp $12^{-1-}$ mice.

The aim of our current investigation was to delineate the unique role of NLRP12 by invoking innate immunity against $K$. pneumoniae by using a human cell system and a mouse model of infection.

\section{RESULTS}

\section{NLRP12 expression is increased in human pneumonic lungs}

To examine whether NLRP12 expression is increased in human lungs, we used lung sections from patients with pneumonia and lung injury because of bacterial infection using immunofluorescence for NLRP12 in pneumonic and uninjured (control) human lungs. Diffused NLRP12 staining was detected in pneumonic lungs, whereas limited NLRP12 staining was observed in these cell types in the lung sections from control patients (Figure 1). In particular, both myeloid cells (neutrophils (lipocalin + ) and macrophages $(\mathrm{CD} 68+))$ and non-myeloid cells (alveolar type II epithelial cells (pro-surfactant C $($ SPC $)+$ )) express NLRP12 in pneumonic/injured lungs (Figure 1a). Furthermore, we used $K$. pneumoniae-infected mouse lungs to examine the expression of NLRP12 in neutrophils $(\mathrm{Gr}-1+)$, type II epithelial cells (pro-SPC + ), and macrophages $(\mathrm{F} 4 / 80+$ ) (Figure 1b). Our findings together indicate that myeloid cells (neutrophils and macrophages) and non-myeloid cells (alveolar type II epithelial cells) show upregulation of NLRP12 in infected lungs.

\section{NLRP12 regulates proinflammatory cytokines/chemokines in human and mouse macrophages}

To determine the function of NLRP12 in human cells, we measured cytokines/chemokines in human peripheral blood monocyte-derived macrophages, following NLRP12 small interfering RNA (siRNA) knockdown, and in Nlrp12 ${ }^{-1-}$ alveolar macrophages, following the infection with the Gram-negative bacterium, K. pneumoniae. Expression of proinflammatory mediators is regulated by nuclear factor$\kappa \mathrm{B}(\mathrm{NF}-\kappa \mathrm{B})$ and mitogen-activated protein kinases. ${ }^{14}$ In addition, histone deacetylases (HDACs) constitute a family of enzymes that have important roles in the epigenetic regulation of gene expression. ${ }^{15}$ Treatment with the specific HDAC inhibitor (trichostatin A) is shown to be essential to induce cytokines in human alveolar epithelial cell line A549 response to bacterial infection. ${ }^{16}$ In siRNA-transfected human monocyte-derived macrophages, we found reduced NF- $\mathrm{BB}$ activation and attenuated levels of IL- 6 , IL- $1 \beta$, and IL-18 (Figure $2 \mathbf{a}$ and b) 3 or $6 \mathrm{~h}$ after K. pneumoniae infection (Figure 2a and b). Moreover, we found reduced HDAC 2, 3, and 5 upregulation and decreased activation of mitogenactivated protein kinase (MAPKs) (p38, extracellular-signalregulated kinase, and c-Jun N-terminal kinase) in NLRP12 siRNA-transfected human cells (Figure $2 \mathbf{c}$ and $\mathbf{d}$ ). In a similar manner in murine alveolar macrophages, we observed 

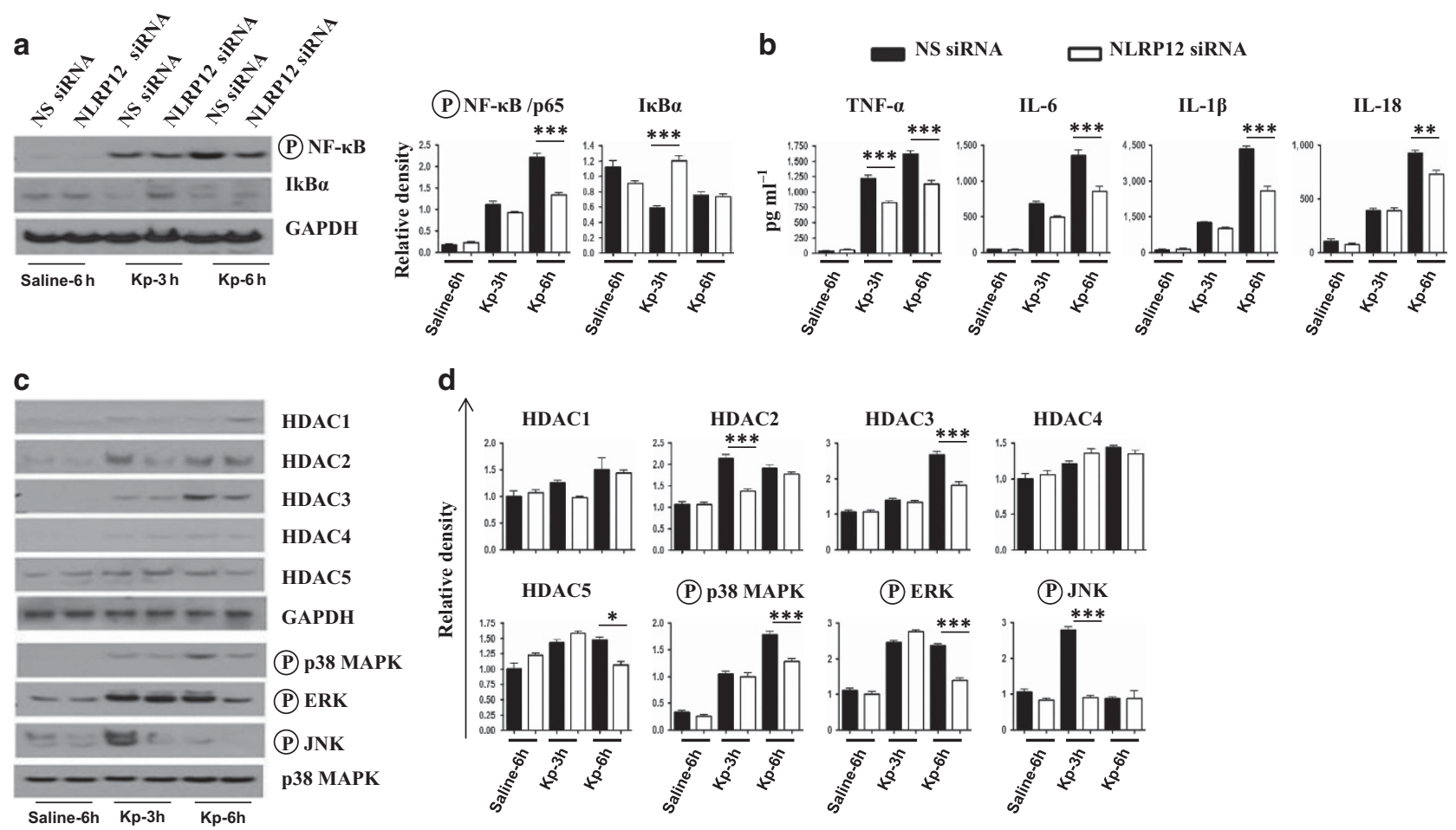

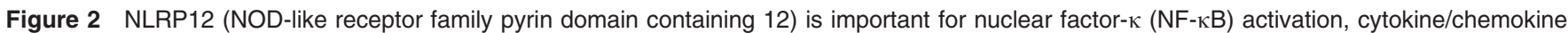
production, histone deacetylase (HDAC) expression, and mitogen-activated protein kinase (MAPK) activation in human macrophages following Klebsiella pneumoniae infection. (a and b) Human monocyte-derived macrophages $\left(0.5 \times 10^{6}\right)$ were transfected with $40 \mathrm{nM}$ NLRP12 small interfering RNA (siRNA) or scrambled siRNA (nonspecific; NS) for $48 \mathrm{~h}$. Cells were then infected with 1 multiplicity of infection (MOI) of $K$. pneumoniaefor 3 or $6 \mathrm{~h}$ and $\mathrm{NF}-\kappa \mathrm{B}$ activation was measured by (a) western blotting, and cytokine/chemokine levels in (b) supernatants were measured by sandwich enzyme-linked immunosorbent assay (ELISA). Representative blots are shown from three independent experiments with identical results. Densitometry was performed using Gel Digitizing Software (Orem, UT) and normalized to glyceraldehyde 3-phosphate dehydrogenase (GAPDH). (c and d) Human macrophages were transfected with siRNA and then infected with $K$. pneumoniae in a similar manner, and cell lysates were used to determine HDAC expression and MAPK activation by western blotting. Representative blots are shown from three independent experiments with identical results. Densitometry was performed using Gel Digitizing Software and normalized to GAPDH. Means \pm s.e. values were obtained from three separate experiments. ${ }^{\star} P<0.05$; ${ }^{* *} P<0.01 ;{ }^{* *} P<0.001$. Error bars represent s.e. ERK, extracellular-signal-regulated kinase; IL-6, interleukin-6; JNK, c-Jun N-terminal kinase; TNF- $\alpha$, tumor necrosis factor- $\alpha$.

decreased cytokines (TNF- $\alpha$, IL-6, and IL-1 $\beta$ ) and neutrophil chemokine (CXCL2/macrophage inflammatory protein-2 (MIP-2)) in Nlrp12 $12^{-1}$ cells, 3 and $6 \mathrm{~h}$ after K. pneumoniae infection (Supplementary data online and Supplementary Figure $\mathbf{1 A}$ and $\mathbf{B}$ ). Attenuated NF- $\mathrm{kB}$ activation, reduced HDAC 1,2 , and 3 upregulation, and decreased activation of MAPKs (p38, extracellular-signal-regulated kinase, and c-Jun $\mathrm{N}$-terminal kinase) was also observed in Nlrp12 $2^{-1-}$ cells (Supplementary Data and Supplementary Figure 1C and D).

\section{NLRP12 regulates host defense against $K$. pneumoniae infection}

To assess the effect of NLRP12 activation in pulmonary defense during extracellular Gram-negative bacterial infection, WT and Nlrp12 $2^{-1-}$ mice were infected intratracheally with two (higher and lower) doses of $\mathrm{K}$. pneumoniae $\left(10^{3}\right.$ or $10^{4}$ colony-forming units (CFUs) per mouse), and survival was monitored up to 15 days after the infection. The Nlrp12 $2^{-1-}$ mouse group displayed attenuated survival to both higher and lower infectious doses (Figure 3a). To determine if reduced survival of Nlrp12 ${ }^{-I-}$ mice after K. pneumoniae infection is dependent on impaired bacterial clearance in the lungs or bacterial dissemination in Nlrp12 $2^{-1-}$ mice, K. pneumoniae $\mathrm{CFU}$ counts were quantified from the whole lung and spleen at 24 and $48 \mathrm{~h}$ after infection (lower dose). Nlrp12 ${ }^{-1-}$ mice demonstrated higher lung, liver, and spleen CFUs as compared with their WT littermates at $48 \mathrm{~h}$ (Figure 3b).

To identify mechanisms that contribute to higher bacterial CFUs in lungs and extrapulmonary organs, we assessed neutrophil recruitment to the airspaces following K. pneumoniae challenge because neutrophil influx is shown to be critical to clear K. pneumoniae infection in tissues. ${ }^{8,17}$ Total white blood cell and neutrophil accumulation in the airspaces of $\mathrm{Nlrp12} 2^{-1-}$ mice was attenuated at $48 \mathrm{~h}$ compared with WT controls (Figure 3c). Consistent with reduced neutrophil recruitment into the airspaces, we also observed reduced neutrophil influx in lung parenchyma (myeloperoxidase activity in lung homogenates) of Nlrp12 ${ }^{-1-}$ mice as compared with WT mice (Figure 3c). To determine if the decreased neutrophil influx is dependent on the production of cytokines/chemokines following K. pneumoniae infection, we measured the expression of cytokines (IL-23, IL-17A, and IL-1 $\beta$ ) and neutrophil 

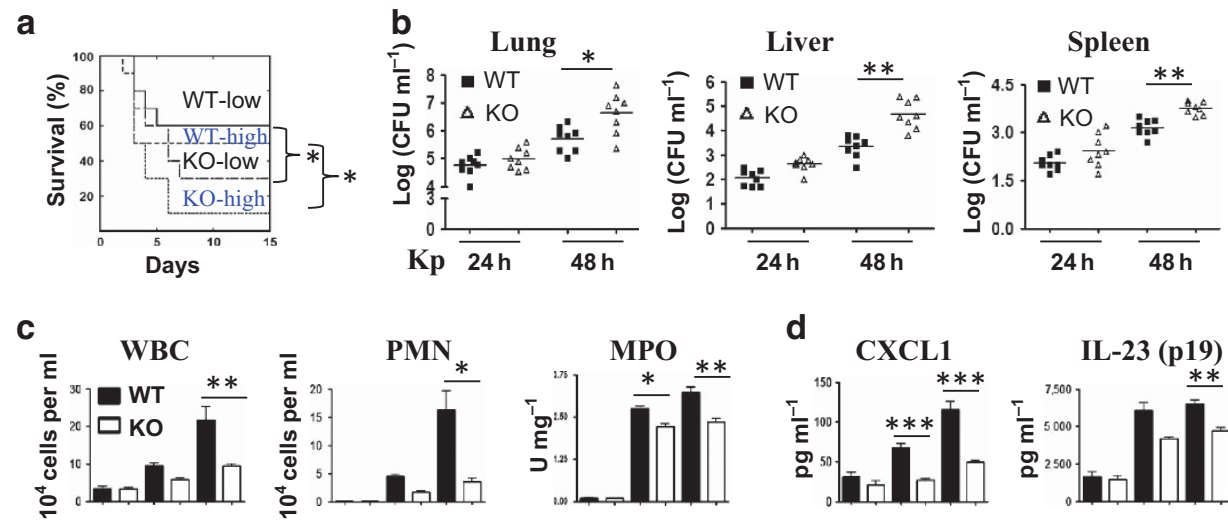

d
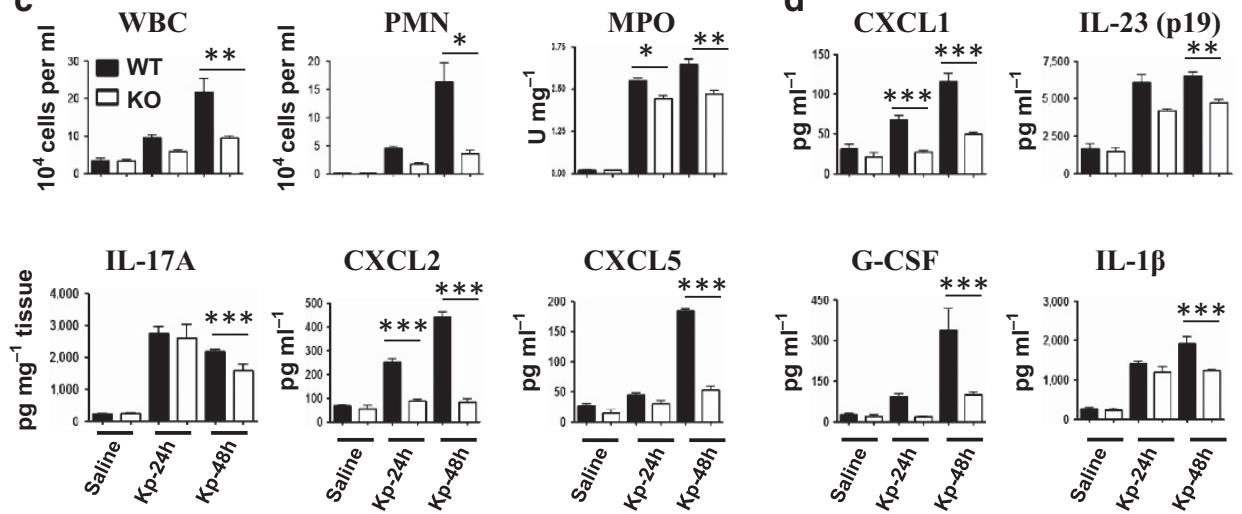

e
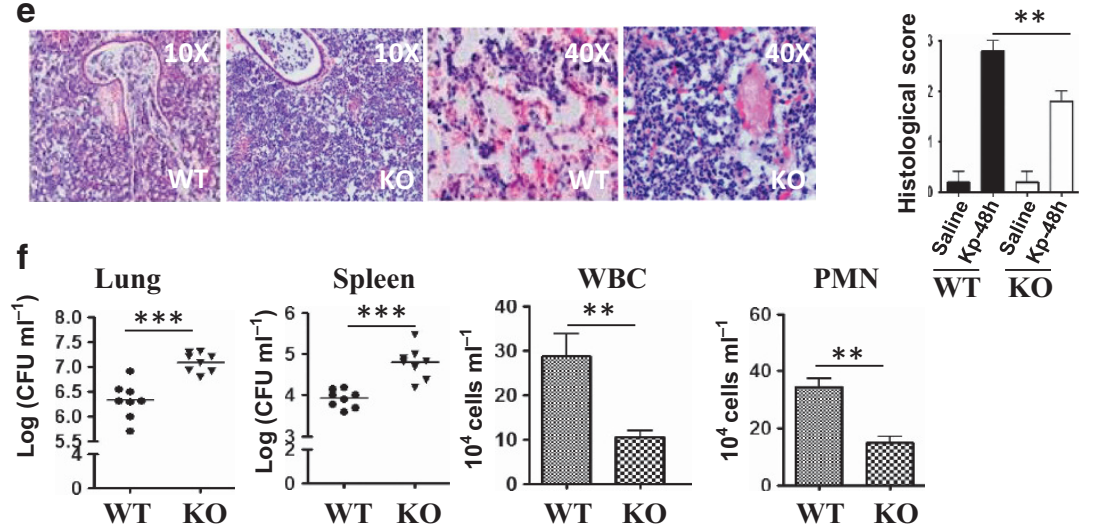

g

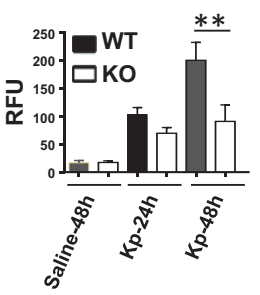

Saline-48h Kp-48h
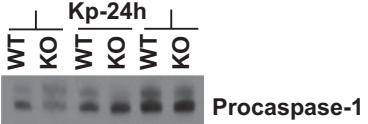

(p50)

caspase-1 (p20)
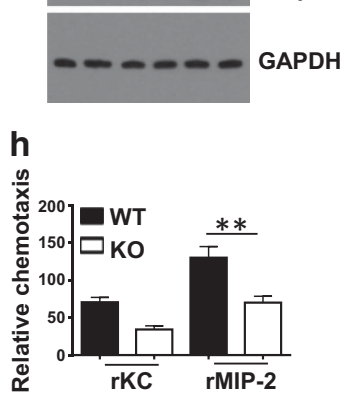

Figure 3 NLRP12 (NOD-like receptor family pyrin domain containing 12) modulates host defense against Klebsiella pneumoniae infection. (a) NIrp12 ${ }^{-1-}$ and C57BL/6 (control) mice were inoculated intratracheally with $10^{3}$ or $10^{4}$ colony-forming units (CFUs) of K. pneumoniae and mortality was monitored up to 15 days ( ${ }^{*} P<0.05$ by log-rank test). Data shown represent $n=20$ mice per group from two representative independent experiments. (b) Mice were infected with $1 \times 10^{3} \mathrm{CFUs}$ of $K$. pneumoniae intratracheally and lung and spleen homogenates were cultured at 24 or $48 \mathrm{~h}$ for bacterial enumeration. Data shown represent mean parenchymal CFUs \pm s.e. $\left({ }^{\star} P<0.05\right.$ comparing wild-type (WT) with $N / r p 12-/-$ mice). (c and d) NIrp12 ${ }^{-/}$ or C57BL/ 6 mice were exposed to $1 \times 10^{3} \mathrm{CFUs}$ of $K$. pneumoniae intratracheal bronchoalveolar lavage fluid (BALF) was collected and (c) total white blood cells, neutrophils, parenchymal neutrophil influx, or (d) cytokine/chemokine levels were enumerated 24 and $48 \mathrm{~h}$ after challenge $(n=7-10$ per group). (e) Mice were inoculated with $1 \times 10^{3} \mathrm{CFUs}$ of $K$. pneumoniae per mouse intratracheally. Lungs were obtained at $48 \mathrm{~h}$ after infection and stained with hematoxylin and eosin (H\&E), and inflammatory changes in histological sections were scored. Shown are representative sections from four mice under each condition with identical results (original magnification, $\times 200$ ). Semiquantitative inflammation score is a quantification of four lung sections in each group. (f) Mice on an A/J background were infected with $1 \times 10^{3} \mathrm{CFUs}$ of $K$. pneumoniae intratracheally and lung and spleen homogenates were used to enumerate bacterial burden, whereas BALF was used to enumerate neutrophil influx at $48 \mathrm{~h}$ after infection. Data shown represent mean \pm s.e. ( $n=7-9$ mice per group). (g) Mice were intratracheally infected with $1 \times 10^{3} \mathrm{CFU}$ of $\mathrm{K}$. pneumoniae and lung homogenates were used to measure caspase-1 activity at 24 and $48 \mathrm{~h}$ after infection ( $n=4-5$ mice per group). Representative blots are shown from four to five mice with similar results. (h) Migration of neutrophils toward keratinocyte chemoattractant (KC) and macrophage inflammatory protein-2 (MIP-2). Neutrophil numbers in the lower chamber of a transwell were enumerated after $3 \mathrm{~h}$ of incubation. Data are a representation of four to six mice per group). ${ }^{\star} P<0.05,{ }^{\star \star} P<0.01$, and ${ }^{\star * \star} P<0.001$. Error bars represent s.e. CXCL1, chemokine (C-X-C motif) ligand 1; GAPDH, glyceraldehyde 3-phosphate dehydrogenase; G-CSF, granulocyte-colony-stimulating factor; IL, interleukin; KO, knock out; MPO, myeloperoxidase; PMN, polymorphonuclear leukocyte; RFU, relative fluorescence unit; WBC, white blood cell.

chemoattractants (CXCL1/keratinocyte chemoattractant (KC), CXCL2/MIP-2, and CXCL5/lipopolysaccharide (LPS)-induced CXC chemokine (LIX)) in bronchoalveolar lavage fluid (BALF) and lung homogenates 24 and $48 \mathrm{~h}$ following $K$. pneumoniae challenge (Figure 3d). Intriguingly, IL-1 $\beta$, IL-23, IL-17A, and granulocyte-colony-stimulating factor levels in $\mathrm{Nlrp} 12^{-/-}$ mice in BALF or lung homogenates were attenuated at $48 \mathrm{~h}$ following the K. pneumoniae challenge (Figure 3d).

Because multiple proinflammatory genes are regulated by NF- $\kappa \mathrm{B}, \mathrm{HDAC}$, and MAPKs, ${ }^{18,19}$ we next investigated the activation of $\mathrm{NF}-\kappa \mathrm{B}$, expression of HDACs, and activation of MAPKs in the lungs of $N l r p 12^{-/-}$mice following 
K. pneumoniae infection. As shown in Supplementary Data and Supplementary Figure 2A and C, NF- $\mathrm{kB}$ activation was reduced in $N$ lrp $12^{-1-}$ mice at 24 and $48 \mathrm{~h}$ following $\mathrm{K}$. pneumoniae challenge. Additionally, Nlrp12 ${ }^{-1-}$ mice infected with $K$. pneumoniae exhibit reduced expression of HDAC2 (Supplementary Data and Supplementary Figure 2D and E), although no change in activation of p38, extracellular-signalregulated kinase, and c-Jun $\mathrm{N}$-terminal kinase was observed at 24 and $48 \mathrm{~h}$ after infection (Supplementary Data and Supplementary Figure 2F and G).

Using semiquantitative histology, WT mice showed severe suppurative bronchopneumonia, whereas $N \operatorname{lrp} 12^{-1-}$ mice displayed moderate suppurative pneumonia $48 \mathrm{~h}$ after $K$. pneumoniae infection (Figure 3e). In contrast, no significant cellular influx and alveolar edema was observed in salinechallenged (control) lungs obtained from either $\mathrm{Nlrp} 12^{-1-}$ or WT animals (data not shown). To demonstrate whether the effect of NLRP12 gene deficiency is mouse strain-specific, we used WT and knockout mice on an A/J background (after 10 generations of backcrossing) and we observed that infected Nlrp12 $2^{-1-}$ mice showed (1) more bacterial burden in the lungs and spleens and (2) reduced neutrophil influx in BALF following the infection (Figure 3f), suggesting that NLRP12 effects are not mouse background-specific.

In prior studies, NLRP12 has been suggested to form inflammasomes to enhance caspase- 1 activation and IL- $1 \beta$ and IL-18 maturation. ${ }^{9,13}$ Therefore, despite measuring IL-1 $\beta$ levels in BALF following the infection, we evaluated caspase-1 activation in the infected lungs using fluorometry and western blotting. We detected a decrease in caspase-1 activity and caspase-1 cleavage in Nlrp12 $12^{-1-}$ lungs following the infection (Figure 3g). Moreover, western blot results demonstrated that a significant amount of procaspase-1 was present in the lungs infected with $K$. pneumoniae (Figure 3g).

In mice, ELR + CXC chemokines, such as CXCL1/KC, CXCL2/MIP-2, and CXCL5/GCP-2/LIX, are known neutrophil chemoattractants. ${ }^{20}$ In a recent investigation, it has been shown that NLRP12 modulates dendritic cell (DC) and myeloid cell migration in a mouse model of contact hypersensitivity. ${ }^{21}$ In this study, DCs and neutrophils obtained from the Nlrp12 ${ }^{-/-}$ mice show attenuated migration towards DC chemoattractants, such as CCL19, CCL21, and CXCL12, and neutrophil chemoattractants, such as CXCL1/KC. Our results also demonstrated attenuated neutrophil migration towards CXCL2/MIP-2, but reduced migration towards KC, which is not statistically significant (Figure $\mathbf{3 h}$ ).

NLRP12 mediates IL-17A differentiation of CD4 + T cells The amount of IL-17A production is reduced in the lungs of Nlrp12 $2^{-1-}$ mice in response to K. pneumoniae (Figure 4). Reduced number of IL-17-producing cells may be because of (1) attenuated recruitment from the bloodstream, and/or (2) augmented differentiation of T-helper type 0 (Th0) cells to become Th17 cells locally. Therefore, we did an in vitro T-cell differentiation assay to determine these possibilities. Our results show diminished differentiation of Th0 cells to Th17 and Th1 cells in Nlrp12-I- mice but no difference between $\mathrm{CD} 4+\mathrm{T}$ cells of $\mathrm{WT}$ and Nlrp12 ${ }^{-1-}$ mice in Th2 differentiation (Figure 4), highlighting the role of NLRP12 in Th17/Th1 differentiation.

\section{Bone marrow-derived NLRP12 is important for host defense}

Next, we asked if host defense against $K$. pneumoniae could be because of recruited bone marrow (BM) (hematopoietic) cells and/or resident alveolar cells. To address this hypothesis, WT or Nlrp12 $2^{-1-}$ mice were lethally irradiated and reconstituted with BM cells from donor WT or Nlrp12 $2^{-1-}$ mice to generate four groups: (1) WT mice reconstituted with WT marrow (WT $\rightarrow$ WT); (2) WT mice reconstituted with $N l r p 12^{-1-}$ marrow $\left(\right.$ Nlrp12 $\left.2^{-1-} \rightarrow \mathrm{WT}\right) ;(3)$ Nlrp12 $2^{-1-}$ mice reconstituted with WT marrow (WT $\rightarrow$ Nlrp12 $12^{-1-}$ ); and (4) Nlrp12 $2^{-1-}$ mice reconstituted with $\mathrm{Nlrp}_{12} 2^{-1-}$ marrow $\left(\mathrm{Nlrp12} 2^{-1-} \rightarrow\right.$ $\mathrm{Nlrp} 12^{-/-}$). Eight weeks after reconstitution, these BM chimera mice were intratracheally inoculated with $K$. pneumoniae, and bacterial burden in the lungs and spleens was determined. We found more bacterial burden in Nlrp12 ${ }^{-1-} \rightarrow \mathrm{Nlrp} 12^{-1-}$ and Nlrp12 $2^{-1-} \rightarrow$ WT chimera mice as compared with WT $\rightarrow$ WT or WT $\rightarrow$ Nlrp $12^{-1-}$ chimera animals (Figure 5a and b). Leukocye/neutrophil recruitment to the lung was attenuated in Nlrp12 $2^{-I-} \rightarrow \mathrm{Nlrp}_{12} 2^{-I-}$ and Nlrp12 $2^{-I-} \rightarrow$ WT chimera mice as compared with $\mathrm{WT} \rightarrow \mathrm{WT}$ or WT $\rightarrow \mathrm{Nlrp} 12^{-1-}$ chimera animals (Figure $\mathbf{5 c}$ and $\mathbf{d}$ ).

\section{NLRP12 is dispensable for pyroptosis}

NLRP12 has previously been shown to induce pyroptosis in response to flagellated bacterial infection, such as Burkholderia pseudomallei ${ }^{22}$ and Salmonella typhimurium. ${ }^{23}$ Pyroptosis is induced by caspase-1 activation by proteolytic cleavage of caspase- $1 .{ }^{24}$ However, annexin $\mathrm{V}$ stains not only pyroptotic cells but also apoptotic cells. ${ }^{25} \mathrm{We}$ detected pyroptosis and/or apoptosis using flow cytometry-based annexin $\mathrm{V}$ binding. As shown in Figure $\mathbf{6 a}$ and $\mathbf{b}$, pyroptosis or apoptosis in neutrophils $(\mathrm{Ly} 6 \mathrm{G}+)$ or macrophages $(\mathrm{EMR} 1+)$ in $K$. pneumoniae-infected lungs and spleens between WT and Nlrp12 $2^{-1-}$ mice was not dfifferent.

\section{Adoptive transfer of CD4 + T cells rescues host defense in $\mathrm{NLRP}^{-1}{ }^{-1}$ mice}

Our findings demonstrated that (1) IL-17A levels were reduced in Nlrp12 $12^{-1-}$ mice following K. pneumoniae infection (Figure 3) and (2) CD4 $+\mathrm{T}$ cells from Nlrp12 ${ }^{-1-}$ mice show attenuated Th17 differentiation (Figure 4). Studies unequivocally demonstrated that $\mathrm{CD} 4+\mathrm{T}$ cells are an important source of IL-17A. ${ }^{26,27}$ To examine if an increase in the number of T cells could rescue NLRP12 deficiency, we adoptively transferred 0.5 million IL- $17+$ CD4 $\mathrm{T}$ cells intratracheally to Nlrp $12^{-/-}$mice at the time of the infection. Transfer of mature WT (IL-17 ${ }^{+/+}$) CD4 + T cells, but not transfer of $I l-17^{-1-} \mathrm{CD} 4+\mathrm{T}$ cells, rescued survival, bacterial load in the lungs and spleen, neutrophil influx, and cytokine/ chemokine expression in lungs (Figure $7 \mathbf{a}-\mathbf{d}$ ). 

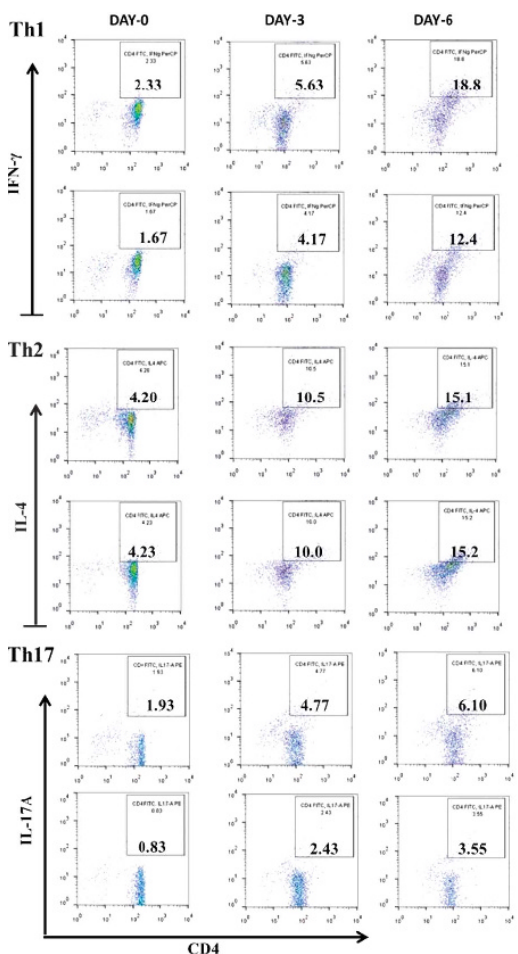
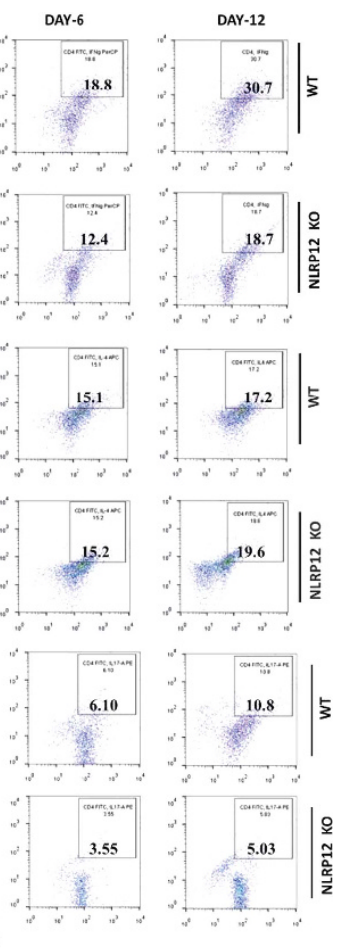

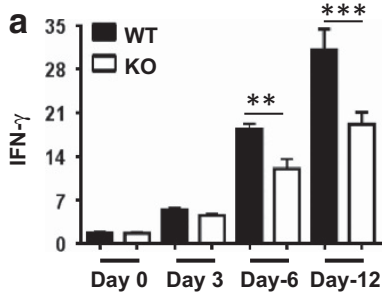

b
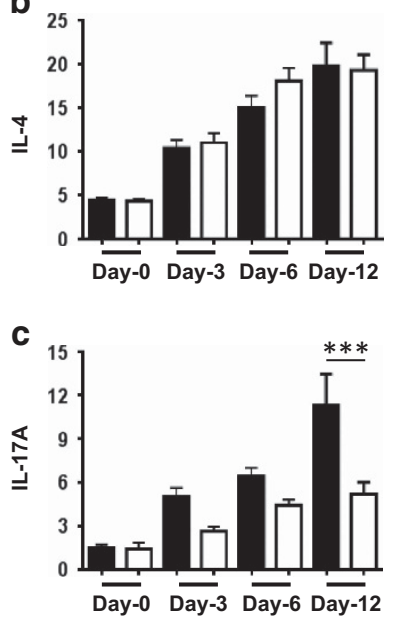

Figure 4 NIrp12-1- mice display attenuated T-helper type 17 (Th17)/Th1 differentiation of CD4 T-cell population. (a-c, right panel) Naive CD4 + T cells from wild-type (WT) and knockout (KO) mice were isolated and stimulated with phorbol 12-myristate 13-acetate (PMA) as described in the Methods section and a representative dot blot has shown. (a-c, left panel) Quantitation of interleukin-17A (IL-17A)-producing CD4 + T cells from three independent experiments ( $n=5-8$ mice per group). ${ }^{* \star} P<0.01$ and ${ }^{* *} P<0.001$. Error bars represent s.e. IFN, interferon; NLRP12, NOD-like receptor family pyrin domain containing 12 .

\section{Adoptive transfer of CXCL1 + macrophages restores host resistance in NLRP12 ${ }^{-I-}$ mice to $K$. pneumonia}

Our data showed that CXCL1, a neutrophil chemoattractant, levels were attenuated in Nlrp12 $2^{-1-}$ mice after K. pneumoniae infection (Figure 3). We have shown that that macrophages are an important source of CXCL1 (Supplementary Data and Supplementary Figure 1A). To examine if an increase in the number of CXCL1 + (WT) macrophages could rescue NLRP12 deficiency, we adoptively transferred $0.5 \times 10^{6} \mathrm{BM}$ macrophages intratracheally to Nlrp12 $12^{-1-}$ mice at the time of the infection. Transfer of mature WT, but not transfer of $\mathrm{Cxcl1}^{-1-}$ macrophages, rescued survival, bacterial burden in the lungs and spleen, neutrophil influx, and cytokine/chemokine expression in lungs (Figure $\mathbf{8 a}$ and $\mathbf{d}$ ).

\section{DISCUSSION}

In humans, mutations in gene encoding NLRP12 are linked to skin rashes, fevers, and joint pains that are similar to what is seen in patients with Familial Cold Autoinflammatory Syndrome. ${ }^{28,29}$ These mutations seem to decrease the ability of NLRP12 protein to attenuate the inflammation, leading to the intermittent episodes of fever as these mutations may lead to increased caspase-1 activity. ${ }^{30,31}$ The host defenses of the human lung include successful elimination of the microbes by resident alveolar macrophages. ${ }^{32,33}$ Any defects in host defense functions in macrophages ultimately lead to infectious complications in the host by excessive bacterial colonization. Our findings conclude that NLRP12 in human macrophages has an important host defense function against a non-flagellated bacterium. This was unexpected and represents the first report of NLRP12-dependent protein induction in these unique human cells in response to $K$. pneumoniae infection.

In mice, both proinflammatory and anti-inflammatory functions of NLRP12 have been demonstrated. ${ }^{9,11,12}$ Initial findings indicate that NLRP12 regulates DC and neutrophil migration both in vitro and in vivo: (a) isolated BM DCs obtained from Nlrp12 $12^{-1-}$ mice show decreased migration toward CCR7 and CXCR4 ligands; (b) the migration of Nlrp12 ${ }^{-1-}$ BM neutrophils to CXCL1/KC was also attenuated by $\sim 50 \%$ in vitro; and (c) experiments also show that Nlrp $12^{-1-}$ DCs display a significantly reduced capacity to migrate to draining lymph nodes in a mouse model of contact hypersensitivity. ${ }^{21}$ Regarding investigations dealing with bacterial pathogens, findings reveal that NLRP12 contributes to host defense against $Y$. pestis in a mouse model of systemic (subcutaneous and intraperitoneal) infection. ${ }^{13}$ Nevertheless, only a single report has addressed the role of NLRP12 in host resistance to infectious agents via the intrapulmonary route. ${ }^{7}$ Using a very high inoculum of $K$. pneumoniae $(74,000$ CFU per mouse), the authors show reduced macrophage and lymphocyte influx and attenuated TNF- $\alpha$ levels in the lungs following the infection, although neutrophil influx and 

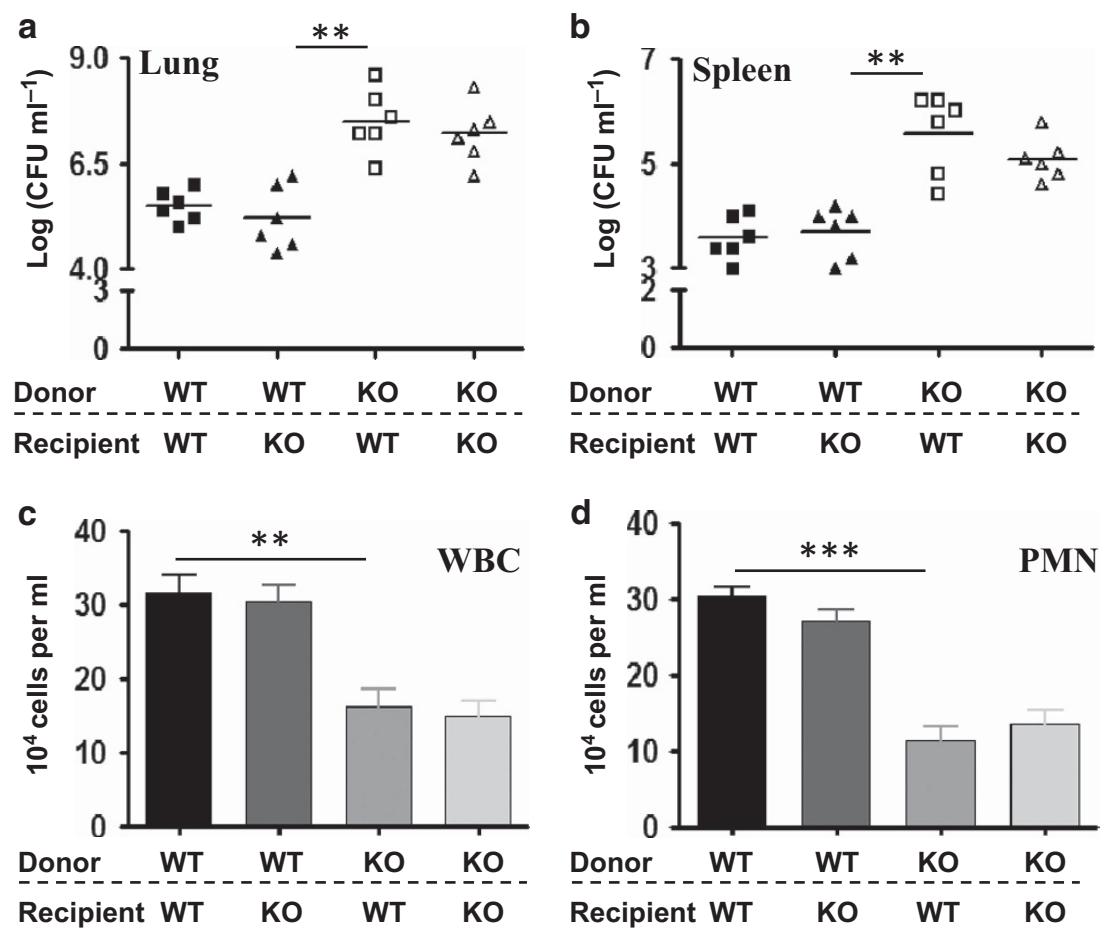

Figure 5 NLRP12 (NOD-like receptor family pyrin domain containing 12)-expressing bone marrow-derived cells are important to clear Klebsiella pneumoniae infection. (a and b) Bone marrow chimeras were generated with wild-type (WT) and NLRP12 ${ }^{-1-}$ mice. Mice were then infected with $1 \times 10^{3}$ colony-forming units (CFUs) of K. pneumoniae/mouse intratracheally and bacterial burden in the (a) lungs and (b) spleens were assessed at (a and $\mathbf{b}) 48 \mathrm{~h}$ after infection. In another set of experiments, bronchoalveolar lavage fluid (BALF) was collected and (c) total white blood cell and (d) neutrophil numbers were enumerated $48 \mathrm{~h}$ after the infection ( $n=5-8$ per group). ${ }^{\star \star} P<0.01$ and ${ }^{\star \star \star}{ }^{*} P<0.001$. Error bars represent s.e. KO, knock out; PMN, polymorphonuclear leukocyte; WBC, white blood cell; WT, wild-type.

bacterial clearance were not different between WT (control) and Nlrp $12^{-1-}$ mice. However, we observed that host survival, bacterial clearance, and neutrophil recruitment to the lungs are dependent on NLRP12 following K. pneumoniae infection. The discrepancy between the published study and our study could be explained by the fact that (1) both studies used different K. pneumoniae strains; (2) Allen et al. ${ }^{7}$ have used an extremely high dose (74,000 CFUs per mouse) and we used a low dose $(1,000$ CFUs per mouse) in all experiments, but used both lower and higher doses of K. pneumoniae (1,000 and 10,000 CFUs per mouse) for survival experiments.

The current study is the first to demonstrate a role for NLRP12 in host resistance against both extracellular pulmonary bacterial pathogens. Redundant roles for inflammasomes may occur for optimal innate immune responses against bacteria. Thus far, two other inflammasomes have been implicated in the regulation of host immunity to K. pneumoniae: $\mathrm{NLRP}^{6}{ }^{6}$ and NLRC4 or IPAF. ${ }^{8}$ The involvement of multiple inflammasomes for host defense against $K$. pneumoniae supports the emerging concept and relates to the cooperative interactions between different inflammasomes during bacterial infection in the host. Although cooperative interactions have not been explored in the lungs, interaction among different inflammasomes has been demonstrated in the gut. ${ }^{34,35}$ Future studies using double or triple knockout mice should explore these interactions in more detail.
It has been demonstrated that neutrophil influx is a critical event to clear $K$. pneumoniae in the lungs as neutrophil depletion before the infection enhanced susceptibility to the infection. ${ }^{8}$ Here, we demonstrate that deletion of NLRP12 leads to augmented susceptibility to intrapulmonary $K$. pneumoniae infection. Additional data illustrate that NLRP12 inhibits bacterial colonization in the lungs and dissemination of K. pneumoniae. This increase in CFUs correlates with decreased neutrophil influx and the production of neutrophil chemoattractants, such as KC, MIP-2, or LIX in the lungs. This is also the first demonstration of an important role for NLRP12 in host resistance against pulmonary infection. Although attenuated production of neutrophil chemoattractants have contributed to reduced neutrophil influx in the lungs, our results also reveal that NLRP12 $2^{-1-}$ neutrophils have an inherent defect towards migrating neutrophil chemoattractants, such as CXCL2/MIP-2. Consistent with this speculation, a previous study shows that the migration of $N l r p 12^{-1-} \mathrm{BM}$ neutrophils towards CXCL1/KC was reduced by $\sim 50 \%$ compared with the neutrophils from control mice. ${ }^{21}$

Although hematopoietic cells in the lung produce several neutrophil chemokines-including $\mathrm{KC}^{36}$ and MIP-2 (ref. 37) - resident cells, such as alveolar epithelial type II cells, produce other neutrophil chemoattractants, such as LIX. ${ }^{38}$ We show that a requirement for NLRP12 signaling predominantly via hematopoietic cells for bacterial clearance 


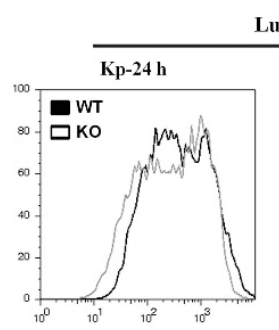

Lung
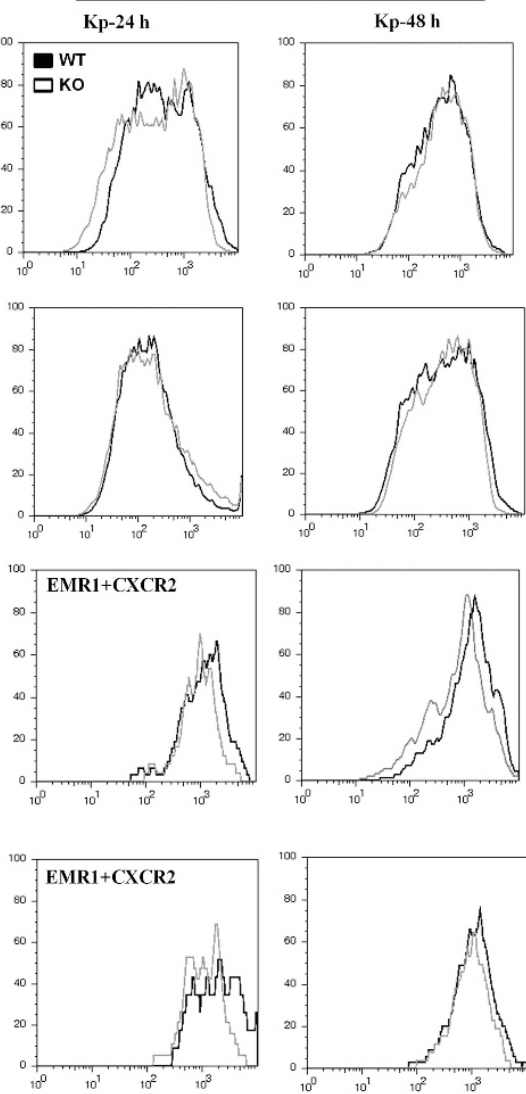
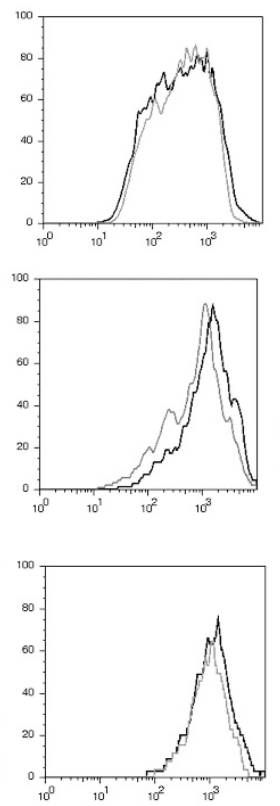
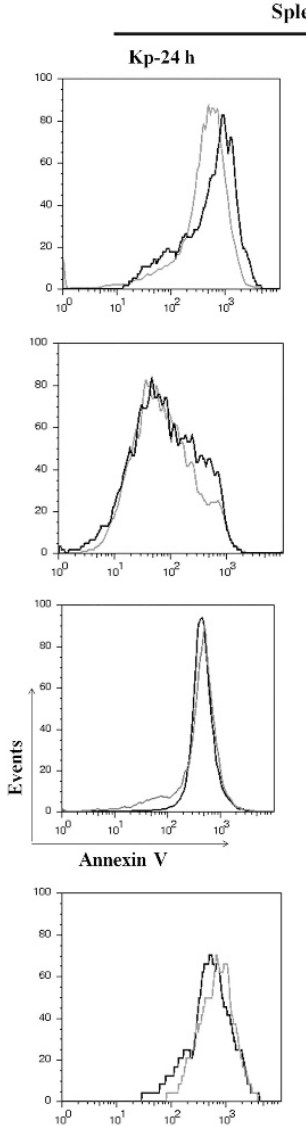

Spleen
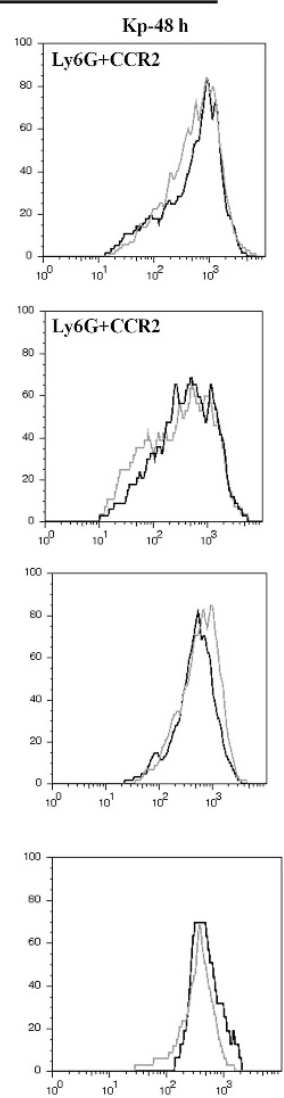

Figure 6 NLRP12 (NLR family pyrin domain containing 12) does not control pyroptosis in macrophages and neutrophils in the lung and spleen following Klebsiella pneumoniae infection. Flow cytometry was performed on $\mathrm{CCR} 2^{+}$or $\mathrm{CXCR} 2^{+}$neutrophils $(\mathrm{Ly} 6 \mathrm{G}+)$ and macrophages $(\mathrm{EMR} 1)$ obtained from the lung and spleen homogenates at 24 and $48 \mathrm{~h}$ following $K$. pneumoniae infection as described in the Methods section. Representative plots from CCR2- or CXCR2-expressing neutrophils and macrophages from three independent experiments ( $n=5$ mice per group). Error bars represent s.e. CCR2, C-C chemokine receptor type 2; CXCR2, C-X-C chemokine receptor type 2; EMR1, epidermal growth factor module-containing mucin-like receptor 1.
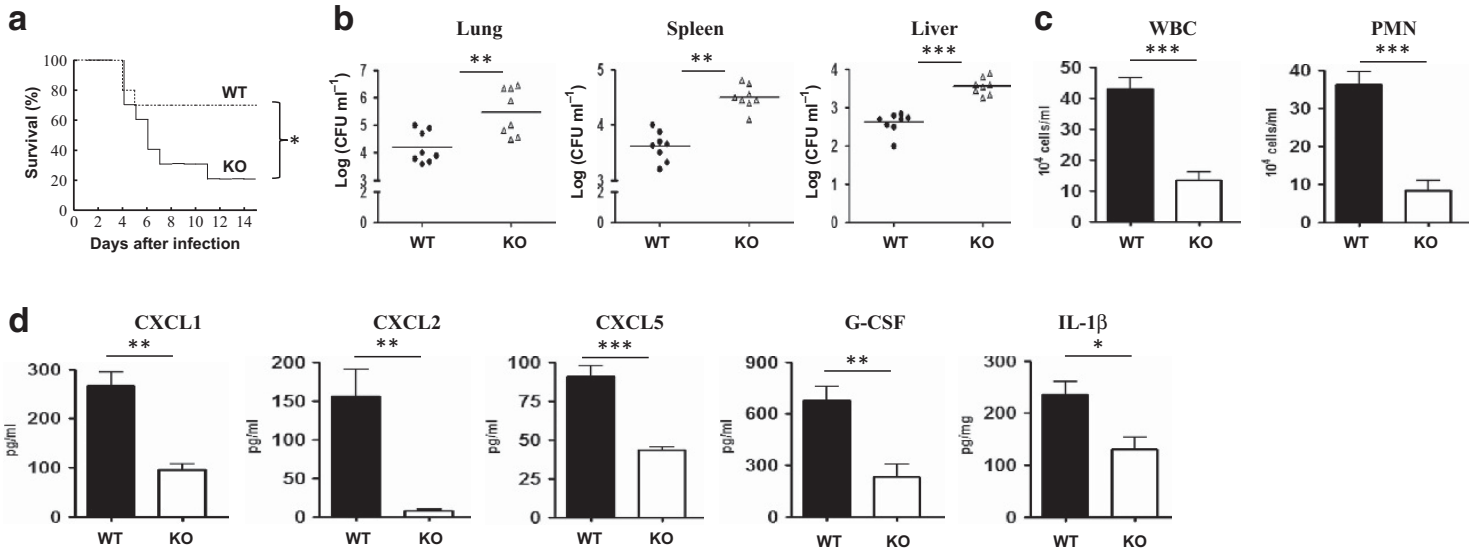

Figure 7 Interleukin-17A (IL-17A) producing CD4 + T cells rescues survival, bacterial clearance, cellular recruitment, and cytokine expression following Klebsiella pneumonia infection. (a and b) NIrp12 ${ }^{-1-}$ mice administered with splenic CD ${ }^{+} \mathrm{T}$ cells $\left(0.5 \times 10^{6}\right.$ per mouse) intratracheally at the time of infection. (a) Survival, bacterial colony-forming units (CFUs) in the (b) lung, spleen, and liver at $48 \mathrm{~h}$ after Klebsiella pneumoniae infection were enumerated ( $n=8$ mice per group). (c) Leukocyte/neutrophil influx and (d) cytokine expression in BALF or lung homogenates was measured at $48 \mathrm{~h}$ after infection. (For survival, $n=20$ mice per group, whereas for other experiments $n=6-9$ mice per group). ${ }^{\star} P<0.05,{ }^{\star \star} P<0.01$, and ${ }^{* \star \star} P<0.001$. Error bars represent s.e. CXCL1, chemokine (C-X-C motif) ligand 1; G-CSF, granulocyte-colony-stimulating factor; IL, interleukin; KO, knock out; NLRP, NOD-like receptor family pyrin domain containing 12; PMN, polymorphonuclear leukocyte; WT, wild-type.

and neutrophil accumulation in the lungs. Our findings are also consistent with earlier reports of the role of either hematopoietic cells or resident cells in infectious or noninfectious lung inflammation: (a) MyD88 derived from hematopoietic cells is more important for LPS-induced expression of TNF- $\alpha$ and IL$12 \mathrm{p} 40,{ }^{39}$ although both hematopoietic and resident cell-derived 
a
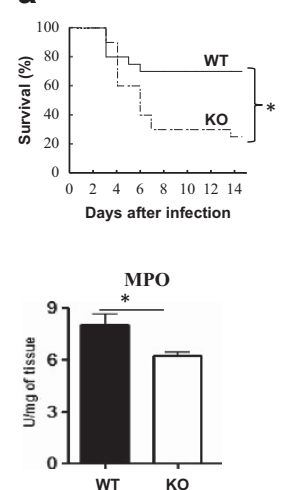

b
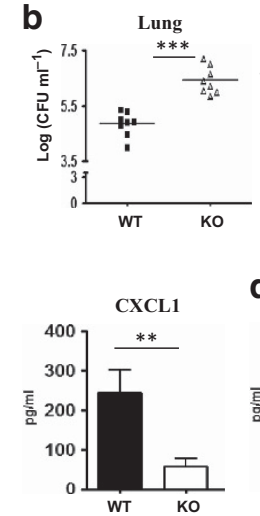
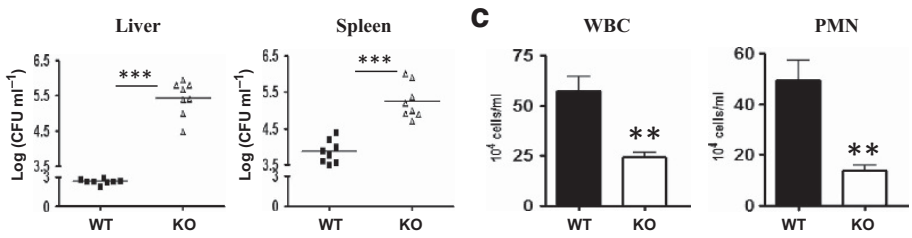

\section{d}
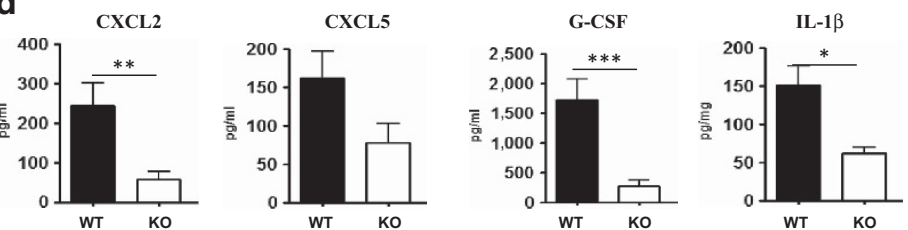

Figure 8 Chemokine ( $\mathrm{C}-\mathrm{X}-\mathrm{C}$ motif) ligand 1 (CXCL1) producing macrophages restores survival, bacterial clearance, leukocyte recruitment, and cytokine production in response to Klebsiella pneumoniae infection. (a and b) NIrp12 ${ }^{-1-}$ mice administered with wild-type (WT) or knockout (KO) bone marrow macrophages $\left(0.5 \times 10^{6}\right.$ per mouse $)$ intratracheally at the time of the infection. At $48 \mathrm{~h}$ after K. pneumoniae infection, (a) survival, bacterial colonyforming units (CFUs) in the (b) lung, spleen, and liver were enumerated ( $n=8$ mice per group). (c) Leukocyte/neutrophil recruitment and (d) cytokine production in bronchoalveolar lavage fluid (BALF) or lung homogenates was measured at $48 \mathrm{~h}$ after infection. (For survival, $n=20$ mice per group, whereas for other experiments $n=6-10$ mice per group.) ${ }^{\star} P<0.05$, ${ }^{\star *} P<0.01$, and ${ }^{\star * \star} P<0.001$. Error bars represent s.e. G-CSF, granulocyte-colonystimulating factor; IL, interleukin; MPO, myeloperoxidase; NLRP, NOD-like receptor family pyrin domain containing; PMN, polymorphonuclear leukocyte; WBC, white blood cell.

MyD88 signaling are essential for LPS-induced neutrophil influx; ${ }^{40,41}$ (b) MD-2 signaling in both hematopoietic and resident cells is essential for neutrophil-mediated inflammation, and the expression of MIP-2, TNF- $\alpha$, and IL- 6 is mediated by both cell types in the lungs after LPS challenge; ${ }^{42}$ and (c) CXCL1/KC produced by both hematopoietic and resident cells is important for bacterial clearance and neutrophil recruitment to the lung upon $K$. pneumoniae infection. ${ }^{43}$ As both hematopoietic cells and resident cells show upregulated expression of NLRP12, these results may lead to the prediction that both cell types contribute to host defense. However, our results highlight the contribution of hematopoietic cell-driven NLRP12 in host defense. Therefore, the inducible expression levels of NLRP12 in hematopoietic cells vs. stromal cells in the lungs following the infection and cell-type-specific responses following $K$. pneumoniae infection need to be determined by future studies to resolve this discrepancy.

A rapid immune response is critical to augmenting host defense. The innate immune system is crucial to rapidly detect infection. The emerging role of inflammasomes as mediators of innate immunity positions them as therapeutic targets. One of the known inflammasome activators, alum, is in widespread use as vaccine adjuvants in humans. The finding that inhibition of NLRP12 can paralyze pulmonary defense could have a deep impact on the strategies to treating and/or preventing bacterial pneumonias.

\section{METHODS}

Immunohistochemistry. For immunofluorescence staining, human lung sections from lungs without evidence of infection, injury, or other diseases $(n=3)$ or from patients who died off pneumonia with acute lung injury/acute respiratory distress syndrome were obtained from a commercial source (Biochain, Newark, CA). These sections were analyzed for NLRP12 immunostaining. Briefly, deparaffinized fixed lung sections were permeabilized with the buffer containing Triton
X-100 (0.1\%) and then blocked with serum. Lung sections were incubated with anti-NLRP12 (Abgent, San Diego, CA) and surface markers including anti-lipocalin antibody $(\mathrm{Ab})$ for polymorphonuclear leukocytes (R\&D Systems, Minneapolis, MN), anti-pro-SPC Ab for type II epithelial cells (Millipore, Billerica, MA), or anti-CD68 $\mathrm{Ab}$ for macrophages (BioLegend, San Diego, CA). For mouse lung sections, we used anti-Gr1 for polymorphonuclear leukocytes (US Biological), anti-pro-SPC for type II epithelial cells, or anti-F4/80 (BioLegend) as surface markers along with anti-NLRP12 Ab (Abgent). Sections were washed and incubated with Alexa-conjugated secondary antibodies (Invitrogen, Carlsbad, CA). Tissue sections were washed and mounted using Vectashield mounting medium (Vector Laboratories, Burlingame, CA) containing DAPI (4',6-diamidino-2phenylindole) stain for nuclear staining. Images were acquired using an Axiocam digital camera connected to a Zeiss Axioskop 2 Plus research microscope (Zeiss, Thornwood, NY).

Human macrophages. Frozen human peripheral blood mononuclear cells were obtained from Astarte Biologics (Redmond, WA) and were used as described in our previous publication. ${ }^{8}$ For monocyte/ macrophage differentiation, monocytes were cultured on plates for up to 7 days in RPMI 1640, containing 5\% fetal bovine serum, $1 \%$ penicillin-streptomycin, and $100 \mathrm{ng} \mathrm{ml}^{-1}$ macrophage colonystimulating factor. For knockdown experiments, a prevalidated pool of siRNA (a cocktail of four siRNAs) for human NLRP12 was obtained from Santa Cruz Biotechnology (Santa Cruz, CA). Cells $\left(0.5 \times 10^{6}\right)$ were transfected with either $40 \mathrm{~nm}$ siRNA or a control siRNA (Santa Cruz Biotechnology) using TransIT-TKO Transfection Reagent from MIRUS (Madison, WI) for $48 \mathrm{~h}$. Cells were then infected with 1 multiplicity of infection (MOI) of K. pneumoniae for $6 \mathrm{~h}$. For cytokine/chemokine assays, supernatants were collected $24 \mathrm{~h}$ after infection. For immunoblotting experiments, macrophages were washed three times with phosphate-buffered saline (PBS) before lysing with urea/CHAPS/Tris buffer supplemented with protease and phosphatase inhibitors.

Mouse macrophages. All mice on a C57BL/6 background were bred in specific pathogen-free rooms within animal facilities at the Louisiana State University. Controls for each experiment were genderand age-matched. Murine alveolar macrophages were isolated from BALF from WT or Nlrp12 $2^{-1-}$ mice as described previously. ${ }^{43,44}$ Mice 
were anesthetized and then killed by cardiac exsanguination. Lungs were lavaged with $0.8 \mathrm{ml}$ sterile saline each time through an intratracheal catheter as described previously, ${ }^{43,45}$ and a total of $8 \mathrm{ml}$ saline was instilled and recovered from each mouse. The lavage fluid was spun at $300 \mathrm{~g}$ for $10 \mathrm{~min}$ to pellet alveolar macrophages. Cells were cultured in 12 -well culture plates at $37^{\circ} \mathrm{C}$ with $5 \% \mathrm{CO}_{2}$ at a concentration of $0.5 \times 10^{6}$ cells per well in $1 \mathrm{ml}$ RPMI 1640 medium (Sigma Chemical, St Louis, MO) supplemented with $10 \%$ fetal bovine serum, $1 \mathrm{~mm}$ pyruvate, $100 \mathrm{U} \mathrm{ml}^{-1}$ penicillin, and $0.1 \mathrm{mg} \mathrm{ml}^{-1}$ streptomycin. After $2 \mathrm{~h}$ of incubation, non-adherent cells were removed with $\mathrm{PBS}$, and the medium was replaced. Cells were then infected with 1 MOI of K. pneumoniae (ATCC; 43816, Manassas, VA) for designated time points. For cytokine studies, media were collected at 3 and $6 \mathrm{~h}$ following the infection. For western blotting, cells were washed three times with PBS and lysed with urea/CHAPS/Tris buffer containing protease and phosphatase inhibitors.

Mice. The 8- to-10-week-old female mice, genetically deficient for NLRP12 (Nlrp12 $\left.{ }^{-1-}\right)^{46}$ or age- and gender-matched WT mice weighing $22-26 \mathrm{~g}$, were used for in vivo experiments. Nlrp12 ${ }^{-1-}$ mice were backcrossed 10 times with age-matched $\mathrm{C} 57 \mathrm{Bl} / 6$ or $\mathrm{A} / \mathrm{J}$ mice. Mice were kept on 12:12 h light-dark cycle with free access to food and water. All animal experiments were approved by the Louisiana State University IACUC.

Pneumonia model. K. pneumoniae serotype 2 strain (ATCC; 43816) was used for a intrapulmonary challenge as described earlier. ${ }^{17,43,45}$ The bacteria were grown for $8 \mathrm{~h}$ at $37^{\circ} \mathrm{C}$ in $50 \mathrm{ml}$ tryptic soy broth with shaking at 225 r.p.m. Bacteria were harvested by centrifuging the culture at $1,200 \mathrm{~g}$ for $2 \mathrm{~min}$ and washed two times in sterile saline. The cells were resuspended in an isotonic saline at a concentration of $10^{3} \mathrm{CFUs}$ per $50 \mu \mathrm{l}$ per mouse. After anesthesia, K. pneumoniae suspension $\left(10^{3} \mathrm{CFUs}\right.$ in $\left.50 \mu \mathrm{l}\right)$ in $0.9 \%$ saline was inoculated via the intratracheal (intrapulmonary) route. The CFUs were enumerated by serially diluting the suspension of initial inoculums and subsequently plating $20 \mu \mathrm{l}$ aliquots of each dilution onto a tryptic soy agar plate and a MacConkey agar plate. Similarly, for counting bacterial CFUs in the lungs and spleen, tissues were homogenized in PBS for 15 and $30 \mathrm{~s}$, respectively, and $20 \mu \mathrm{l}$ of homogenates were plated in 10 -fold serial dilutions onto tryptic soy agar and MacConkey agar plates. The survival of NLRP12 $2^{-1-}$ and WT mice was monitored for up to 15 days following inoculation with $K$. pneumoniae. For adoptive transfer experiments, $0.5 \times 10^{6} \mathrm{IL}-17 \mathrm{~A}+/ \mathrm{IL}-17 \mathrm{~A}-\mathrm{CD} 4+\mathrm{T}$ cells or CXCL1 +/CXCL1 - BM macrophages were intratracheally administered at the time of the infection.

BALF collection. The animals were killed, and the trachea was exposed and subsequently cannulated with a 20-gauge catheter as described earlier. ${ }^{43,45}$ BALF was collected four times by instilling $0.8 \mathrm{ml}$ of PBS containing heparin and dextrose. Total leukocytes in BALF were enumerated by counting on a hemocytometer, whereas BAL differential leukocyte cell counts were determined by standard light microscopy. The remaining $(2 \mathrm{ml})$ of the undiluted cell-free BALF was passed through a $0.22 \mu \mathrm{m}$ filter and used for the determination of cytokine/chemokine levels.

Lung isolation. Following the infection, the whole (nonlavaged) lungs were excised and snap frozen. For long-term storage, these lung tissues were stored at $-70^{\circ} \mathrm{C}$ and used for cytokine/chemokine determination, western blots, and myeloperoxidase activity assay. Lung tissue was briefly homogenized in $2 \mathrm{ml}$ PBS supplemented with $0.1 \%$ Triton X-100 and complete protease inhibitor (1 tablet per $50 \mathrm{ml}$ media), and the resulting homogenates were centrifuged at $12,000 \mathrm{~g}$ per $20 \mathrm{~min}$. The supernatants were harvested, passed through a $0.22 \mu \mathrm{m}$ filter, and used as required.

Myeloperoxidase activity. The lung homogenates were resuspended in $50 \mathrm{mM}$ potassium phosphate buffer ( $\mathrm{pH}$ 6.0) supplemented with $0.5 \%$ hexadecyltrimethylammonium bromide, as described in the previous publications. ${ }^{17,38,42,43,45}$ Samples were then sonicated, incubated at $60{ }^{\circ} \mathrm{C}$ for $2 \mathrm{~h}$, and assayed for myeloperoxidase activity in a hydrogen peroxide- $O$-dianisidine buffer at $460 \mathrm{~nm}$. Absorbance was measured at $460 \mathrm{~nm}$ using a spectrophotometer. The increase activity was calculated between 0 and $90 \mathrm{~s}$.

Cytokines/chemokines. Cytokines/chemokines were determined by sandwich enzyme-linked immunosorbent assay as described earlier. ${ }^{17,42,43,45}$ The minimum detection limit of the assay was $2 \mathrm{pg} \mathrm{ml}^{-1}$ of protein. For mouse lungs, TNF- $\alpha$, IL-6, LIX, MIP-2, IL-23, IL-17A, IL-1 $\beta$, and IL-18 concentrations were normalized to the total protein concentration in the samples measured. Results are expressed as $\mathrm{pg} \mathrm{mg}^{-1}$ of total protein for lung tissue and in $\mathrm{pg} \mathrm{ml} \mathrm{m}^{-1}$ for BALF.

Semiquantitative histology. The lungs were perfused from the right ventricle of heart with an isotonic saline, 24 and $48 \mathrm{~h}$ after infection, and harvested. For hematoxylin and eosin staining, lungs were fixed in $4 \%$ phosphate-buffered formalin, processed in paraffin blocks, and cut into fine sections ( $5 \mu \mathrm{m}$ in thickness). Semiquantitative histology was performed by a Veterinary Pathologist in a blinded manner according to the following scoring scale: 0 , no inflammatory cells (macrophages or neutrophils) are present in section; $1,<5 \%$ of section is infiltrated by inflammatory cells; $2,5-10 \%$ of section is infiltrated by inflammatory cells; and $3,>10 \%$ of section is infiltrated by inflammatory cells, as indicated in our earlier publications. ${ }^{45,47}$

Caspase-1 activation. (A) Fluorometry: Infected or control lungs were used to make single-cell suspension. A total of 50 cells per well were used in a 96-well plate to measure caspase- 1 activity according to the manufacturer's recommendation (Biovision, Milpitas, CA). At the end of incubation, samples were measured at a 400 -nm excitation filter and $505-\mathrm{nm}$ emission. Increase in fluorescence activity was plotted as relative fluorescence units.

(B) Western blotting: The lungs were harvested at the designated times and homogenized in $1 \mathrm{ml}$ of PBS containing $0.1 \%$ Triton X-100 supplemented with the cocktail of complete protease and phosphatase inhibitors as described in earlier publications. ${ }^{48}$ Mouse anticaspase- 1 $\mathrm{Ab}$ (AdipoGen, CA) at a concentration of $1 \mu \mathrm{g} \mathrm{ml}^{-1}$ was used.

Chemotaxis. Neutrophil transmigration assay was performed in a Transwell system using 24-well tissue culture plates with a pore size of $3.0 \mu \mathrm{m}$ as described in a prior publication. ${ }^{49}$ Chemoattractants, either recombinant KC $(1 \mu \mathrm{g}$ per $0.5 \mathrm{ml})$ or MIP-2 $(1 \mu \mathrm{g}$ per $0.5 \mathrm{ml})$, and PBS supplemented with bovine serum albumin $\left(2 \mu \mathrm{g} \mathrm{ml}^{-1}\right)$ was added to each of the lower wells in the chamber. A total of $0.1 \times 10^{6}$ LPS-activated neutrophils (polymorphonuclear leukocytes) in Dulbecco's modified Eagle's medium supplemented with $0.1 \%$ bovine serum albumin was added to every well of the upper chamber. Following incubation at at $37{ }^{\circ} \mathrm{C} 5 \% \mathrm{CO}_{2}$ for $3 \mathrm{~h}$, the cells from 10 fields in the lower plate were counted using an inverted microscope. The number of polymorphonuclear leukocytes in lower chamber is indicated as relative chemotaxis.

Th1/Th2/Th17 differentiation. Th1/Th2/Th17 differentiation has been performed as described previously. ${ }^{50,51}$ Cells were washed and resuspended in PBS followed by blocking with Fc receptor-blocking reagent. Cells were surface stained with anti-CD4 and intracellularly with anti-interferon- $\gamma$, -IL-4, or -IL-17A. FlowJo software (Ashland, OR) was used for data analysis.

BM transplantation. BM chimera experiments were performed as described in earlier publications. ${ }^{17,42,43}$ Recipient groups were $\gamma$-irradiated from a cesium source in two 525 -rad doses separated by $3 \mathrm{~h}$. $\mathrm{BM}$ was flushed from tibias and femurs from donor mice, and a total of $8 \times 10^{6} \mathrm{BM}$ cells were injected into the tail veins of lethally irradiated recipient mice. Reconstituted mice were treated with $0.2 \%$ neomycin sulfate for the first 2 weeks after transplantation. Bacterial challenge experiments were performed 8 weeks after BM 
reconstitution. In another set of experiments, we used donor cells expressing green fluorescent protein. Blood sample was collected from recipient mice at 6 and 8 weeks after reconstitution, and hematological parameters, such as total WBC counts and differential counts, were measured. Using flow cytometry, we found that $>75-85 \%$ of blood leukocytes were derived from donor marrow at the time the mice were used for experiments (6-8 weeks after transplantation.

Pyroptosis or apoptosis. Lung or spleen digests from C57BL/6 (WT) or Nlrp12 $2^{-1-}$ mice challenged with K. pneumoniae for 24 or $48 \mathrm{~h}$ were used to determine cells undergoing pyroptosis as outlined in the previous publications. ${ }^{8}$ Briefly, lung and spleens cell suspensions were passed through a $0.70 \mu \mathrm{m}$ filter. Following two PBS washings, cells were FcR blocked and aliquoted for surface staining with conjugated PerCP anti-mouse Gr-1/Ly6G or EMR1 and APC anti-mouse CCR 2 or CXCR2. Red blood cells were lysed by adding $\mathrm{NH}_{4} \mathrm{Cl}$ lysing buffer. Cells were resuspended in $1 \times$ binding buffer containing $5 \mu \mathrm{l}$ of Annexin $\mathrm{V}$-FITC and $5 \mu \mathrm{l}$ of propidium iodide according to the manufacturer's protocol (Annexin $\mathrm{V}$ apoptosis detection Kit from BD Pharmingen, San Jose, CA). The cell suspension was vortexed and incubated for $15 \mathrm{~min}$ in the dark at room temperature. A total of $100 \mu \mathrm{l} 1 \times$ binding buffer was added, and cells were analyzed by flow cytometry. CCR2 + or CXCR2 + Gr-1/Ly6G (neutrophils) and EMR1 (macrophages) that were positive for Annexin V-FITC and negative for propidium iodide are shown in histograms.

Adoptive transfer of CD4 \pm T cells and macrophages. Splenic CD ${ }^{+}$ $\mathrm{T}$ cells were isolated and made single-cell suspensions. Cell suspensions were washed, red blood cells were lysed and CD4 $+\mathrm{T}$ cells were isolated by negative selection from single-cell suspension using the EasySep cell separation procedure (StemCell Technologies, Vancouver, BC, Canada). Resulting cell preparations were resuspended to a final density of $0.5 \times 10^{6}$ cells per $50 \mu \mathrm{l}$ PBS for intratracheal administration. BM from femur and tibia was flushed and marrow was passed through a 21-gauge needle four to six times to dissociate the cells. Red blood cells were lysed using $1 \times$ red blood cell lysis buffer. Cell suspension was washed with PBS two times and cells were resuspended in Dulbecco's modified Eagle's medium $+5 \%$ fetal bovine serum + penicillin/streptomycin containing 2 million cells per $\mathrm{ml}$ with macrophage colony-stimulating factor $\left(25 \mathrm{ng} \mathrm{ml}^{-1}\right)$ and seeded for 6-7 days. Fresh BM-derived macrophage growth medium was added on days 3 and 5, and the formation of mature BM-derived macrophage was evaluated after 7 days using flow cytometry analysis to detect cells expressing CD11b and F4/80. The resulting cell preparations were resuspended to a final density of $0.5 \times 10^{6}$ cells per $50 \mu \mathrm{l}$ PBS for intratracheal administration.

Statistics. Data are expressed as mean \pm s.e.m. Analysis of variance, followed by Bonferroni's post hoc analysis, was performed for comparisons among multiple groups. All statistical calculations were performed using the InStat software and GraphPad Prism 4.0 (GraphPad Software, La Jolla, CA). All experiments were performed three times, with the exception of the survival experiments, which were performed two times. The survival results were compared by Wilcoxon's signed-rank test. A $P$-value ${ }^{*}<0.05,{ }^{* *}<0.01$, and $* * *<0.001$ was considered significant.

SUPPLEMENTARY MATERIAL is linked to the online version of the paper at http://www.nature.com/mi

\section{ACKNOWLEDGMENTS}

This work was supported by Scientist Awards from the Flight Attendant Medical Research Institute (CIA and YCSA to S.J.; YCSA to S.C. and S.B.) and grants from the NIH (R01 HL-091958 and R01 Al-113720 to S.J. and R15-1R15ES023151-01 to S.B. We thank Millennium Pharmaceuticals for providing NLRP12 $2^{-/-}$mice. We also thank the Lung Biology members Mary Leissinger, Liliang Jin, Ritwij Kulkarni, Pankaj Baral, and K. Jeyagowri for helpful discussions.

\section{DISCLOSURE}

The authors declared no conflict of interest.

c) 2016 Society for Mucosal Immunology

\section{REFERENCES}

1. Mizgerd, J.P. Lung infection—a public health priority. PLoS Med. 3, e76 (2006).

2. Endimiani, A. et al. Emergence of blaKPC-containing Klebsiella pneumoniae in a long-term acute care hospital: a new challenge to our healthcare system. J. Antimicrob. Chemother. 64, 1102-1110 (2009).

3. Mataseje, L.F. et al. Plasmid comparison and molecular analysis of Klebsiella pneumoniae harbouring bla(KPC) from New York City and Toronto. J. Antimicrob. Chemother. 66, 1273-1277 (2011).

4. Ferrand, J. \& Ferrero, R.L. Recognition of extracellular bacteria by NLRs and its role in the development of adaptive immunity. Front. Immunol. 4, 344 (2013).

5. Leissinger, M., Kulkarni, R., Zemans, R.L., Downey, G.P. \& Jeyaseelan, S. Investigating the role of nucleotide-binding oligomerization domain-like receptors in bacterial lung infection. AmJ. Respir. Crit. Care Med. 189, 1461-1468 (2014).

6. Willingham, S.B. et al. NLRP3 (NALP3, Cryopyrin) facilitates in vivo caspase-1 activation, necrosis, and HMGB1 release via inflammasomedependent and -independent pathways. J. Immunol. 183, 2008-2015 (2009).

7. Allen, I.C. et al. Characterization of NLRP12 during the in vivo host immune response to Klebsiella pneumoniae and Mycobacterium tuberculosis. PLoS One 8, e60842 (2013).

8. Cai, S., Batra, S., Wakamatsu, N., Pacher, P. \& Jeyaseelan, S. NLRC4 inflammasome-mediated production of IL-1beta modulates mucosal immunity in the lung against Gram-negative bacterial infection. J. Immunol. 88, 5623-5635 (2012).

9. Wang, L. et al. PYPAF7, a novel PYRIN-containing Apaf1-like protein that regulates activation of NF-kappa B and caspase-1-dependent cytokine processing. J. Biol. Chem. 277, 29874-29880 (2002).

10. Chen, G.Y. Role of Nlrp6 and NIrp12 in the maintenance of intestinal homeostasis. Eur. J. Immunol. 44, 321-327 (2014).

11. Zaki, M.H. et al. The NOD-like receptor NLRP12 attenuates colon inflammation and tumorigenesis. Cancer Cell 20, 649-660 (2011).

12. Allen, I.C. et al. NLRP12 suppresses colon inflammation and tumorigenesis through the negative regulation of noncanonical NF-kappaB signaling. Immunity 36, 742-754 (2012).

13. Vladimer, G.I. et al. The NLRP12 inflammasome recognizes Yersinia pestis. Immunity 37, 96-107 (2012).

14. Takeda, K., Kaisho, T. \& Akira, S. Toll-like receptors. Annu. Rev. Immunol. 21, 335-376 (2003).

15. Delcuve, G.P., Khan, D.H. \& Davie, J.R Roles of histone deacetylases in epigenetic regulation: emerging paradigms from studies with inhibitors. Clin. Epigenet. 4, 5 (2012).

16. Schmeck, B. et al. Histone acetylation and flagellin are essential for Legionella pneumophila-induced cytokine expression. J. Immunol. 181, 940-947 (2008).

17. Batra, S., Cai, S., Balamayooran, G. \& Jeyaseelan, S. Intrapulmonary administration of leukotriene $B(4)$ augments neutrophil accumulation and responses in the lung to Klebsiella infection in CXCL1 knockout mice. J. Immunol. 188, 3458-3468 (2012).

18. Shakespear, M.R., Halili, M.A., Irvine, K.M., Fairlie, D.P. \& Sweet, M.J. Histone deacetylases as regulators of inflammation and immunity. Trends Immunol. 32, 335-343 (2011).

19. Batra, S., Balamayooran, G. \& Sahoo, M.K. Nuclear factor-kappaB: a key regulator in health and disease of lungs. Arch. Immunol. Ther. Exp. (Warsz) 59, 335-351 (2011).

20. Bhatia, M., Zemans, R.L. \& Jeyaseelan, S. Role of chemokines in the pathogenesis of acute lung injury. Am. J. Respir. Cell Mol. Biol. 46, 566-572 (2012).

21. Arthur, J.C. et al. Cutting edge: NLRP12 controls dendritic and myeloid cell migration to affect contact hypersensitivity. J. Immunol. 185, 4515-4519 (2010). 
22. Ceballos-Olvera, I., Sahoo, M., Miller, M.A., Del Barrio, L. \& Re, F. Inflammasome-dependent pyroptosis and IL-18 protect against Burkholderia pseudomallei lung infection while IL-1beta is deleterious. PLOS Pathogen. 7, e1002452 (2011).

23. Miao, E.A. et al. Innate immune detection of the type III secretion apparatus through the NLRC4 inflammasome. Proc. Natl. Acad. Sci. USA 107, 30763080 (2010).

24. Strowig, T., Henao-Mejia, J., Elinav, E. \& Flavell, R. Inflammasomes in health and disease. Nature 481, 278-286 (2012).

25. Miao, E.A., Rajan, J.V. \& Aderem, A. Caspase-1-induced pyroptotic cell death. Immunol. Rev. 243, 206-214 (2011).

26. Yao, Z. et al. Herpesvirus Saimiri encodes a new cytokine, IL-17, which binds to a novel cytokine receptor. Immunity 3, 811-821 (1995).

27. Tsai, H.C., Velichko, S., Hung, L.Y. \& Wu, R. IL-17A and Th17 cells in lung inflammation: an update on the role of Th17 cell differentiation and IL-17R signaling in host defense against infection. Clin. Dev. Immunol. 2013, 267971 (2013).

28. Macaluso, F. et al. Polymorphisms in NACHT-LRR (NLR) genes in atopic dermatitis. Exp. Dermatol. 16, 692-698 (2007).

29. Jeru, I. et al. Mutations in NALP12 cause hereditary periodic fever syndromes. Proc. Natl. Acad. Sci. USA 105, 1614-1619 (2008).

30. Jeru, I. et al. Identification and functional consequences of a recurrent NLRP12 missense mutation in periodic fever syndromes. Arthritis Rheum. 63, 1459-1464 (2011).

31. Zhong, Y., Kinio, A. \& Saleh, M. Functions of NOD-like receptors in human diseases. Front. Immunol. 4, 333 (2013).

32. Goldstein, E., Lippert, W. \& Warshauer, D. Pulmonary alveolar macrophage. Defender against bacterial infection of the lung. J. Clin. Invest. 54, 519-528 (1974).

33. Gordon, S.B. \& Read, R.C. Macrophage defences against respiratory tract infections. Br. Med. Bull. 61, 45-61 (2002).

34. Nunes, T. \& de Souza, H.S. Inflammasome in intestinal inflammation and cancer. Mediat. Inflamm. 2013, 654963 (2013).

35. Hao, L.Y., Liu, X. \& Franchi, L. Inflammasomes in inflammatory bowel disease pathogenesis. Curr. Opin. Gastroenterol. 29, 363-369 (2013).

36. Bozic, C.R. et al. Expression and biologic characterization of the murine chemokine KC. J. Immunol. 154, 6048-6057 (1995).

37. Driscoll, K.E. et al. Cloning, expression, and functional characterization of rat MIP-2: a neutrophil chemoattractant and epithelial cell mitogen. J. Leukocyte Biol. 58, 359-364 (1995).

38. Jeyaseelan, S. et al. Induction of CXCL5 during inflammation in the rodent lung involves activation of alveolar epithelium. Am. J. Respir. Cell Mol. Biol. 32, 531-539 (2005).
39. Noulin, N. et al. Both hemopoietic and resident cells are required for MyD88-dependent pulmonary inflammatory response to inhaled endotoxin. J. Immunol. 175, 6861-6869 (2005).

40. Skerrett, S.J., Liggitt, H.D., Hajjar, A.M., Ernst, R.K., Miller, S.I. \& Wilson, C.B. Respiratory epithelial cells regulate lung inflammation in response to inhaled endotoxin. Am. J. Physiol. Lung Cell. Mol. Physiol. 287, L143-L152 (2004).

41. Quinton, L.J., Jones, M.R., Robson, B.E., Simms, B.T., Whitsett, J.A. \& Mizgerd, J.P. Alveolar epithelial STAT3, IL-6 family cytokines, and host defense during Escherichia coli pneumonia. Am. J. Respir. Cell Mol. Biol. 38, 699-706 (2008).

42. Cai, S., Zemans, R.L., Young, S.K., Worthen, G.S. \& Jeyaseelan, S. Myeloid differentiation protein-2-dependent and -independent neutrophil accumulation during Escherichia coli pneumonia. Am. J. Respir. Cell Mol. Biol. 40, 701-709 (2009).

43. Cai, S., Batra, S., Lira, S.A., Kolls, J.K. \& Jeyaseelan, S. CXCL1 regulates pulmonary host defense to Klebsiella infection via CXCL2, CXCL5, NF-kappaB, and MAPKs. J. Immunol. 185, 6214-6225 (2010).

44. Xu, J., Xu, F. \& Barrett, E. Metalloelastase in lungs and alveolar macrophages is modulated by extracellular substance $\mathrm{P}$ in mice. Am. J. Physiol. Lung Cell. Mol. Physiol. 295, L162-L170 (2008).

45. Cai, S., Batra, S., Shen, L., Wakamatsu, N. \& Jeyaseelan, S. Both TRIF- and MyD88-dependent signaling contribute to host defense against pulmonary Klebsiella infection. J. Immunol. 183, 6629-6638 (2009).

46. Sutterwala, F.S., Mijares, L.A., Li, L., Ogura, Y., Kazmierczak, B.I. \& Flavell, R.A. Immune recognition of Pseudomonas aeruginosa mediated by the IPAF/ NLRC4 inflammasome. J. Exp. Med. 204, 3235-3245 (2007).

47. Balamayooran, G., Batra, S., Balamayooran, T., Cai, S. \& Jeyaseelan, S. Monocyte chemoattractant protein 1 regulates pulmonary host defense via neutrophil recruitment during Escherichia coli infection. Infect. Immun. 79, 2567-2577 (2011).

48. Jin, L., Batra, S., Douda, D.N., Palaniyar, N. \& Jeyaseelan, S. CXCL1 contributes to host defense in polymicrobial sepsis via modulating $T$ cell and neutrophil functions. J. Immunol. 193, 3549-3558 (2014).

49. Balamayooran, G., Batra, S., Theivanthiran, B., Cai, S., Pacher, P. \& Jeyaseelan, S. Intrapulmonary G-CSF rescues neutrophil recruitment to the lung and neutrophil release to blood in Gram-negative bacterial infection in MCP-1 ${ }^{-1}$ mice. J. Immunol. 189, 5849-5859 (2012).

50. Fang, Y., Yu, S., Ellis, J.S., Sharav, T. \& Braley-Mullen, H. Comparison of sensitivity of Th1, Th2, and Th17 cells to Fas-mediated apoptosis. J. Leukocyte Biol. 87, 1019-1028 (2010).

51. Stummvoll, G.H. et al. Th1, Th2, and Th17 effector T cell-induced autoimmune gastritis differs in pathological pattern and in susceptibility to suppression by regulatory T cells. J. Immunol. 181, 1908-1916 (2008). 